\section{One-Pot Formal Dehydrogenative Ketone Synthesis from Aldehydes and Non-activated Hydrocarbons}

\author{
Kenzo Yahata,* Shin Yoshioka, Shuhei Hori, \\ Shu Sakurai, Yuki Kaneko, Kai Hasegawa, and \\ Shuji Akai
}

Graduate School of Pharmaceutical Sciences, Osaka University; 1-6 Yamada-oka, Suita, Osaka 565-0871, Japan.

Received January 24, 2020; accepted February 3, 2020; advance publication released online February 19, 2020

Ketones are a fundamental functionality found throughout a range of natural and synthetic compounds, making their synthesis essential throughout the chemical disciplines. Herein, we describe a one-pot synthesis of ketones via decatungstate-mediated formal dehydrogenative coupling between aldehydes and non-activated hydrocarbons. A variety of substituted benzaldehydes and cycloalkanes could be used in the optimized reaction to produce the desired ketones in moderate yields. The decatungstate photocatalyst functions in two reactions in this synthesis, catalyzing both the coupling and oxidation steps of the process. Notably, the reaction displays both high atom economy and sustainability, as it uses light and oxygen as key energy sources.

Key words photo catalysis; ketone synthesis; $\mathrm{C}-\mathrm{H}$ activation; one-pot reaction

\section{Introduction}

Ketones are among the most fundamental functional groups in organic chemistry and are constituents of a wide range of organic molecules. Although various routes for ketone synthesis have been reported, most require relatively expensive starting materials, such as organic halides and organometallic reagents. ${ }^{1-19)}$ We recently reported the coupling of aldehydes and non-activated hydrocarbons using $\mathrm{CrCl}_{3}(3 \text { eq. })^{20)}$ and tetrabutylammonium decatungstate (TBADT; $10 \mathrm{~mol} \%)^{21-41)}$ (Chart 1a). During this work, a small quantity of ketone 4 was observed in the crude mixture. Side product $\mathbf{4}$ is likely produced through oxidation of the primary product alcohol

(a) Previous Work
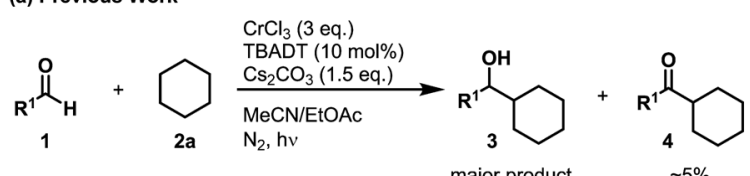

major product

(b) This Work
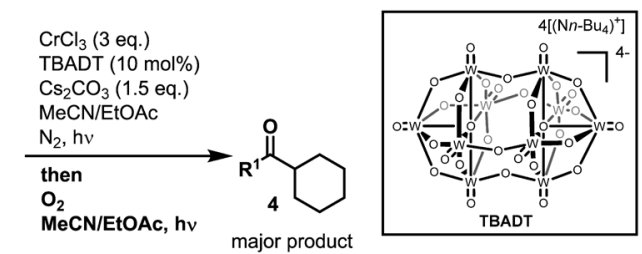

Chart 1. (a) Coupling Reaction between Aldehydes and Non-activated Hydrocarbons (b) One-Pot Formal Dehydrogenative Ketone Synthesis
3 by TBADT and contaminating oxygen ${ }^{42-44)}$ (Fig. 1). Notably, this reaction was promoted by UV light and oxygen, which are clean and sustainable energy sources. Moreover, the overall transformation occurred via highly atom-economic cross-dehydrogenative coupling ${ }^{45)}$ between aldehydes and nonactivated hydrocarbons nominally. We therefore sought to promote the oxidation of alcohols into ketones in a single flask.

Herein, we describe a novel, one-pot formal dehydrogenative synthesis of ketones from aryl aldehydes and nonactivated hydrocarbons (Chart $1 \mathrm{~b}$ ). This reaction proceeds via TBADT-mediated $\mathrm{C}-\mathrm{H}$ activation and oxidation using oxygen

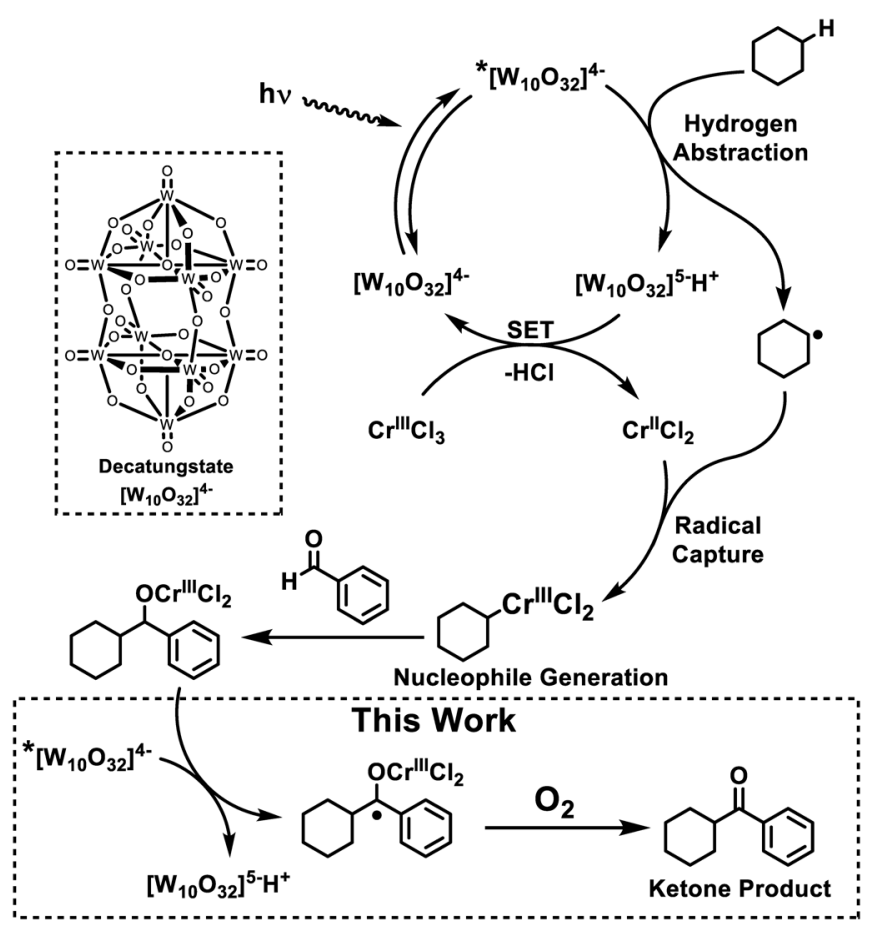

Fig. 1. Reaction Mechanism

Table 1. Optimization of One-Pot Ketone Synthesis ${ }^{a)}$

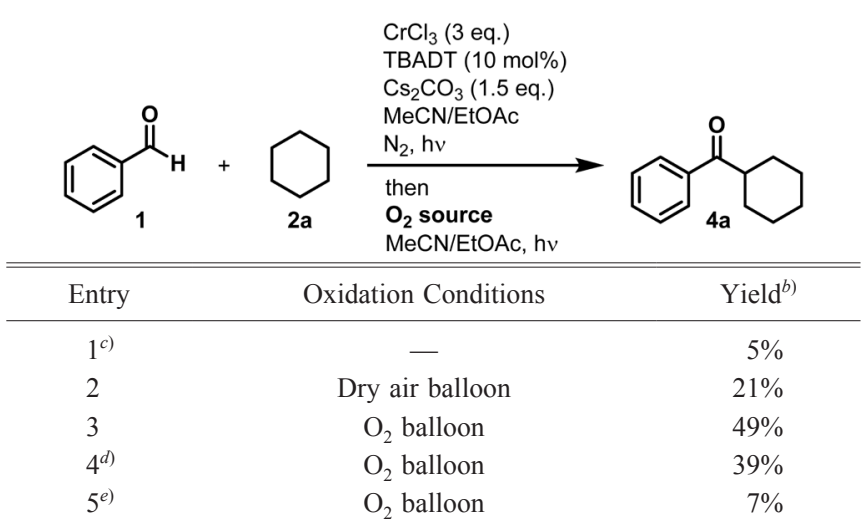

a) Reaction conditions: 1a ( $0.20 \mathrm{mmol}, 1$ eq.), 2a (30 eq.), $\mathrm{CrCl}_{3}$ (3 eq.), TBADT $(10 \mathrm{~mol} \%), \mathrm{Cs}_{2} \mathrm{CO}_{3}$ (1.5 eq.), MeCN/EtOAc $(1: 1,0.1 \mathrm{M}), 40 \mathrm{~W} 390 \mathrm{~nm}$ Kessil lamp, fan, $48 \mathrm{~h}$ for each entry. Then, $\mathrm{O}_{2}$ source, $40 \mathrm{~W} 390 \mathrm{~nm}$ Kessil lamp, fan, $24 \mathrm{~h}$ unless otherwise noted. b) All yields are of $\mathbf{4 a}$ isolated by $\mathrm{SiO}_{2}$ chromatography. $c$ ) Reaction was stopped after the first step, and no second oxidation step was conducted. $d$ ) The second oxidation step was stopped after $12 \mathrm{~h} . e$ ) The second oxidation step was conducted in dark. 
Table 2. Substrate Scope of One-Pot Ketone Synthesis ${ }^{a}$

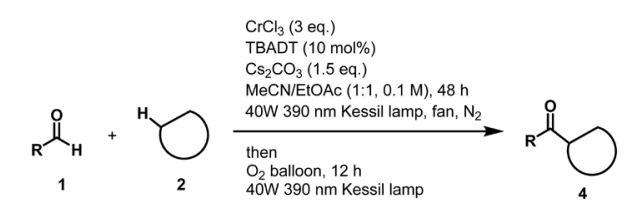

\begin{tabular}{|c|c|c|c|c|}
\hline Entry & 1 & 2 & 4 & Yield $^{\text {b) }}$ \\
\hline 1 & $1 \mathrm{a}$ & $2 \mathbf{a}$ & & $49 \%$ \\
\hline 2 & . & $2 \mathbf{a}$ & & $20 \%$ \\
\hline 3 & & $2 a$ & & $48 \%$ \\
\hline 4 & & $2 a$ & & $33 \%$ \\
\hline 5 & & $2 a$ & & $37 \%$ \\
\hline 6 & & $2 a$ & & $45 \%$ \\
\hline 7 & & $2 a$ & & $23 \%$ \\
\hline 8 & & $2 a$ & & $19 \%$ \\
\hline $9^{c)}$ & $1 \mathrm{a}$ & $\bigcup_{2 b}$ & & $24 \%$ \\
\hline $10^{\mathrm{c})}$ & $1 \mathrm{a}$ & & & $31 \%$ \\
\hline 11 & $1 \mathrm{a}$ & & & $32 \%$ \\
\hline $12^{\text {d) }}$ & $1 \mathrm{a}$ & DMA & & $0 \%$ \\
\hline $13^{\mathrm{d})}$ & $1 \mathrm{a}$ & anisole & & $0 \%$ \\
\hline
\end{tabular}

a) Reaction conditions: 1a $(0.20 \mathrm{mmol}, 1$ eq. $), \mathbf{2 a}$ (30 eq.), $\mathrm{CrCl}_{3}$ (3 eq.), TBADT $(10 \mathrm{~mol} \%), \mathrm{Cs}_{2} \mathrm{CO}_{3}$ (1.5 eq.), MeCN/EtOAc (1:1, 0.1 M), $40 \mathrm{~W} 390 \mathrm{~nm}$ Kessil lamp, fan, $48 \mathrm{~h}$, then $\mathrm{O}_{2}$ balloon, $40 \mathrm{~W} 390 \mathrm{~nm}$ Kessil lamp, fan, $24 \mathrm{~h}$. b) All yields are of isolated 4. c) 2 (20 eq.) was used. d) 2 was used as a cosolvent: $1(0.80 \mathrm{mmol})$ $\mathrm{Cs}_{2} \mathrm{CO}_{3}$ (1.5 eq.), $\mathrm{CrCl}_{3}$ (3 eq.), TBADT (10 mol\%), MeCN/EtOAc/2 (2:1:3, $0.067 \mathrm{M}$ ), two $40 \mathrm{~W} 390 \mathrm{~nm}$ Kessil lamps, fan, $48 \mathrm{~h}$. then $\mathrm{O}_{2}$ balloon, two $40 \mathrm{~W}$ $390 \mathrm{~nm}$ Kessil lamps, fan, $24 \mathrm{~h}$.

as the terminal oxidant.

\section{Results and Discussion}

The reaction conditions were optimized using benzaldehyde (1a) and cyclohexane (2a) (Table 1). The initial coupling step was performed using our previously optimized conditions: $\mathrm{CrCl}_{3}$ (3 eq.), TBADT (10 mol\%), $\mathrm{Cs}_{2} \mathrm{CO}_{3}$ (1.5 eq.), $\mathrm{N}_{2}$ atmosphere, and $390 \mathrm{~nm}$ irradiation ${ }^{21)}$ (Chart 1). Following completion of the coupling reaction, the system was opened and a balloon filled with dry air was attached. The reaction was then continued for an additional $24 \mathrm{~h}$ to provide the desired ketone 4a in $21 \%$ yield, along with the unreacted coupling product alcohol 3a in 35\% yield (entry 2). We then changed the dry air to an oxygen balloon, which increased the yield of $4 \mathbf{a}$ to $49 \%$ (entry 3 ). Decreasing the reaction time $(12 \mathrm{~h})$ for the second oxidation decreased the yield of $\mathbf{4 a}$ to $39 \%$ (entry 4 ). When the second oxidation step was performed without UV light, the yield of $\mathbf{4 a}$ decreased dramatically (7\%) (entry 5), resembling the yield of $\mathbf{4 a}(5 \%)$ obtained when only the first oxidation step was performed (entry 1). From this work, we concluded that the second treatment of the crude coupling product under an oxygen atmosphere with UV irradiation for $24 \mathrm{~h}$ completed the conversion of alcohol 3a into ketone $4 \mathbf{a}$ and that both oxygen and UV are essential for the transformation.

Having established the optimized conditions, we next investigated the scope of the reaction (Table 2). Various aldehydes $\mathbf{1}$ could be employed in the reaction with cyclohexane, although the yields of the corresponding ketones 4 were moderate (19-49\%) (entries 1-8). Substituted benzaldehydes bearing a range of functionalities, including bromo, methoxy, and ester groups, were well-tolerated under the reaction conditions to give the desired ketones $\mathbf{4 c - e}$ in $33-48 \%$ yield (entries 3-6), similar to that of the unsubstituted 4a (49\%) (entry 1). For the substrate bearing a $t$-butyldimethylsilyl (TBS)-oxy group, the non-TBS protected ketone was obtained in $15 \%$ yield along with the desired product $4 \mathrm{~h}$ (19\%) (entry 8$)$. Other cycloalkanes, including cyclopentane (2b), cyclooctane (2c), and norbornane (2d), could also function as coupling partners in this reaction (entries 9-11). Unfortunately, more attractive nucleophile precursors, such as $N, N$-dimethylacetoamide (DMA) and anisole, did not afford the desired ketones $\mathbf{4}$, although their corresponding alcohols $\mathbf{3}$ were isolated in 72 and 40\% yield, respectively (entries 12 and 13).

\section{Conclusion}

We have developed a one-pot formal dehydrogenative coupling between hydrocarbons and aldehydes. Although the yields are moderate, this route displays several advantages over traditional ketone syntheses: (1) non-activated hydrocarbons are commercially available and pre-functionalization is not required; (2) the reaction is atom-economical; (3) the same photocatalyst, TBADT, functions in both stages of the reaction, i.e., the hydrocarbon/aldehyde coupling and oxidation of the resulting alcohol to the ketone; and (4) the ketone-forming step requires only the addition of $\mathrm{O}_{2}$ and light, which are green and sustainable energies. Studies focused on increasing the yield and substrate scope of this novel reaction are currently underway in our research group.

Acknowledgments This work was supported in part by a JSPS Grant-in-Aid for Young Scientists (Grant Number: JP18K14868), the Teijin Pharma Award in Synthetic Organic Chemistry Japan, a Grant-in-Aid from the Tokyo Biochemical Research Foundation, the Keihanshin Consortium for Fostering the Next Generation of Global Leaders in Research (K-CONNEX), established by Building of Consortia for the Development of Human Resources in Science and Technology, Ministry of Education, Culture, Sports, Science and Technology (MEXT), and the Platform Project for Supporting Drug Discovery and Life Science Research (Basis for Supporting Innovative Drug Discovery and Life Science Research (BINDS)) from AMED (Grant Number: JP19am0101084). 
Conflict of Interest The authors declare no conflict of interest.

Supplementary Materials The online version of this article contains supplementary materials.

\section{References}

1) Onaka M., Matsuoka Y., Mukaiyama T., Chem. Lett., 10, 531-534 (1981).

2) Oçafrain M., Devaud M., Troupel M., Perichon J., J. Chem. Soc. Chem. Commun., 2331-2332 (1995).

3) Dolhem E., Oçafrain M., Nédélec J. Y., Troupel M., Tetrahedron, 53, 17089-17096 (1995).

4) Oçafrain M., Devaud M., Nédélec J. Y., Troupel M., J. Organomet. Chem., 560, 103-107 (1998).

5) Oçafrain M., Dolhem E., Nédélec J. Y., Troupel M., J. Organomet. Chem., 571, 37-42 (1998).

6) Tokuyama H., Yokoshima S., Yamashita T., Fukuyama T., Tetrahedron Lett., 39, 3189-3192 (1998).

7) Dolhem E., Barhdadi R., Folest J., Nédélec J. Y., Troupel M., Tetrahedron, 57, 525-529 (2001).

8) Wotal A. C., Weix D. J., Org. Lett., 14, 1476-1479 (2012).

9) Yin H., Zhao C., You H., Lin K., Gong H., Chem. Commun., 48, 7034 (2012)

10) Cherney A. H., Kadunce N. T., Reisman S. E., J. Am. Chem. Soc., 135, 7442-7445 (2013).

11) Wotal A. C., Ribson R. D., Weix D. J., Organometallics, 33, 58745881 (2014).

12) Zhang X., Wang Z., Fan X., Wang J., J. Org. Chem., 80, $10660-$ 10667 (2015).

13) Joe C. L., Doyle A. G., Angew. Chem. Int. Ed., 55, 4040-4043 (2016).

14) Ai Y., Ye N., Wang Q., Yahata K., Kishi Y., Angew. Chem. Int. Ed. 56, 10791-10795 (2017).

15) Amani J., Molander G. A., Org. Lett., 19, 3612-3615 (2017).

16) Kumar V. P., Babu V. S., Yahata K., Kishi Y., Org. Lett., 19, $2766-$ 2769 (2017).

17) Ackerman L. K. G., Martinez Alvarado J. I., Doyle A. G., J. Am. Chem. Soc., 140, 14059-14063 (2018).

18) Shi R., Hu X., Angew. Chem. Int. Ed., 58, 7454-7458 (2019).

19) Wang J., Cary B. P., Bayer P. D., Gellman S. H., Weix D. J., Angew. Chem. Int. Ed., 58, 12081-12085 (2019).

20) Although the reaction requires an excess amount of $\mathrm{CrCl}_{3}$, chromium salts are low toxic in the +2 and +3 oxidation states; oralrat $\mathrm{LD} 50$ for $\mathrm{Cr}_{2} \mathrm{O}_{3}>2700 \mathrm{mg} / \mathrm{kg}$. Chromium(III) and Its Inorganic Compounds., "The MAK-Collection for Occupational Health and Safety.”: 〈DOI: 10.1002/3527600418.mb1606583vee4614〉, 2014.

21) Yahata K., Sakurai S., Hori S., Yoshioka S., Kaneko Y., Hasegawa
K., Akai S., Org. Lett., 22, 1199-1203 (2020).

22) Dondi D., Cardarelli A. M., Fagnoni M., Albini A., Tetrahedron, 62 , 5527-5535 (2006).

23) Dondi D., Fagnoni M., Albini A., Chem. Eur. J., 12, 4153-4163 (2006).

24) Ravelli D., Zema M., Mella M., Fagnoni M., Albini A., Org. Biomol. Chem., 8, 4158-4164 (2010).

25) Ravelli D., Albini A., Fagnoni M., Chem. Eur. J., 17, 572-579 (2011).

26) Ravelli D., Montanaro S., Zema M., Fagnoni M., Albini A., $A d v$. Synth. Catal., 353, 3295-3300 (2011).

27) Ryu I., Tani A., Fukuyama T., Ravelli D., Fagnoni M., Albini A., Angew. Chem. Int. Ed., 50, 1869-1872 (2011).

28) Montanaro S., Ravelli D., Merli D., Fagnoni M., Albini A., Org. Lett., 14, 4218-4221 (2012).

29) Ryu I., Tani A., Fukuyama T., Ravelli D., Montanaro S., Fagnoni M., Org. Lett., 15, 2554-2557 (2013).

30) Halperin S. D., Fan H., Chang S., Martin R. E., Britton R., Angew. Chem. Int. Ed., 53, 4690-4693 (2014).

31) Okada M., Fukuyama T., Yamada K., Ryu I., Ravelli D., Fagnoni M., Chem. Sci, 5, 2893-2898 (2014).

32) Bonassi F., Ravelli D., Protti S., Fagnoni M., Adv. Synth. Catal., 357, 3687-3695 (2015).

33) West J. G., Huang D., Sorensen E., Nat. Commun., 6, 10093 (2015).

34) Murphy J. J., Bastida D., Paria S., Fagnoni M., Melchiorre P., $\mathrm{Na}$ ture (London), 532, 218-222 (2016).

35) Quattrini M. C., Fujii S., Yamada K., Fukuyama T., Ravelli D., Fagnoni M., Ryu I., Chem. Commun., 53, 2335-2338 (2017).

36) Fukuyama T., Nishikawa T., Yamada K., Ravelli D., Fagnoni M., Ryu I., Org. Lett., 19, 6436-6439 (2017).

37) Fukuyama T., Yamada K., Nishikawa T., Ravelli D., Fagnoni M., Ryu I., Chem. Lett., 47, 207-209 (2018).

38) Ravelli D., Fagnoni M., Fukuyama T., Nishikawa T., Ryu I., ACS Catal., 8, 701-713 (2018).

39) Perry I. B., Brewer T. F., Sarver P. J., Schultz D. M., DiRocco D. A., MacMillan D. W. C., Nature (London), 560, 70-75 (2018).

40) Yuan Z., Yang H., Malik N., Colvić M., Weber D. S., Wilson D., Bénard F., Martin R. E., Warren J. J., Schaffer P., Britton R., ACS Catal., 9, 8276-8284 (2019).

41) Fukuyama T., Nishikawa T., Ryu I., Eur. J. Org. Chem., DOI: 10.1002/ejoc.201901135 (2019), in press.

42) Tzirakis M. D., Lykakis I. N., Orfanopoulos M., Chem. Soc. Rev., 38, 2609-2621 (2009).

43) Symeonidis T. S., Tamiolakis I., Armatas G. S., Lykakis I. N., Photochem. Photobiol. Sci., 14, 563-568 (2015).

44) Laudadio G., Govaerts S., Wang Y., Ravelli D., Koolman H. F. Fagnoni M., Djuric S. W., Noël T., Angew. Chem. Int. Ed., 57, 4078-4082 (2018).

45) Li C.-J., Acc. Chem. Res., 42, 335-344 (2009). 